\title{
ACARDIA FETUS: INCIDENTALLY DISCOVERED PLACENTAL MASS
}

Ayyagari Sudha1, Namala Vivekanand², Rooma Sinha ${ }^{3}$, N Bharadwaj4.

1. Consultant Pathologist, Department of Pathology, Medwin Hospitals, Hyderabad.

2. Associate Professor, Department of Pathology, Rajiv Gandhi Institute of Medical Sciences, Adilabad.

3. Consultant Gynecologist, Department of Obstetrics \& Gynaecology, Medwin Hospitals, Hyderabad.

4. Post Graduate, Department of Pediatrics, MNR Medical College, Sangareddy.

\section{CORRESPONDING AUTHOR:}

Dr. Namala Vivekanand,

Flat no 204, Venkatadri Apartments, SVRS Brundavan Complex,

Behind Ghmc Office, Saroornagar,

Hyderabad, Andhrapradesh,

Pin Code 500035.

Email- drnvivek2002@yahoo.com

ABSTRACT: Fetus acardia is a rare and serious complication of monozygotic twin gestation which usually presents as a placental mass. We encountered a case of acardia fetus as a skin covered placental mass which was incidentally detected during delivery of a live female baby. Grossly central area of the mass was bony hard and showed vertebral organization. Periphery was firm with a myxoid appearance. Histology of the mass revealed flattened epidermis, below which is a loose myxoid-mesenchymal tissue containing fat and blood vessels.

KEY WORDS: Fetus acardia, Placenta, Histopathology, Twin, Organogenesis.

MESH TERMS: Monozygotic, Twin, Placenta, Female, Organogenesis, APGAR score, Vertebral column, Umbilical cord,

INTRODUCTION: Acardia syndrome is a rare complication affecting one percent of monozygotic twins (1 in 35000 pregnancies) where one twin fails to develop the brain and thoracic structures. However co-twin more often develops normally, ${ }^{[1]}$ runs a high risk of perinatal morbidity and mortality due to heart failure and prematurity.[2] This congenital malformation is due to twin reversed arterial perfusion (TRAP) sequence in which abnormal vascular anastomoses in the placenta allow inter-twin transfusion. ${ }^{[3]}$

These fetuses differ greatly in size, gross appearance and degree of organogenesis but all lack a functioning heart. ${ }^{[4]}$ Careful examination of the case shows organization in the form of vertebral column in the centre covered by a loose myxoid-mesenchymal tissue and skin.

CASE REPORT: A 26 years old lady, Gravida2 Para1 Live1 delivered a live female baby at full term weighing 2.6kg with Apgar score of 8/10 at $1 \mathrm{~min}$ and 10/10 at $5 \mathrm{~min}$. There were no obvious external and internal anomalies in the baby. At the time of placental delivery, a skin covered mass was also discovered attached to the placenta by another umbilical cord [Figure 1].

Grossly the placenta measured $15 \mathrm{~cm}$ in diameter and $4 \mathrm{~cm}$ thick. Umbilical cord was central, measuring $13 \mathrm{~cm}$ long, $1.0 \mathrm{~cm}$ diameter containing 3 blood vessels (two arteries and one vein). A globular skin covered mass measuring $6 \mathrm{~cm} \times 5 \mathrm{~cm}$ was seen attached to the fetal surface by a 
separate cord measuring $8 \mathrm{~cm}$ long, $0.5 \mathrm{~cm}$ in diameter containing two blood vessels (one artery and vein). Wharton's jelly was absent in this cord. Central area of the mass was bony hard and showed vertebral organization [Figure 2]. Periphery was firm with a myxoid appearance. There was no other organ or limb. Histology of the mass revealed flattened epidermis, below which is a loose myxoid-mesenchymal tissue containing fat and blood vessels [Figure 3].This skin covered mass is diagnosed as Acardia Fetus.

Sections from the placenta show huge numbers of villi in various planes and varying in diameter from large main stem villi to very small terminal branch villi. Blood vessels are seen in large villi. Development of placenta correlates with the gestational age. There were no placental abnormalities. However, perfusion studies were not done on follow up there were no hemodynamic abnormalities in the live baby.

DISCUSSION: There are only few case reports of skin covered placental masses lacking significant internal and external tissue organization. Presence of a central skeleton in the form of linear bony hard nodules, probably representing the vertebral column, and attachment to the placenta by a separate umbilical cord helped us in ruling out a teratoma.

Acardia fetuses vary from being amorphous shapeless masses to others exhibiting rudimentary trunk and limb development and rarely, they are remarkably well developed. Habbal has reported a rare association of an acardiac anencephalic monozygotic twin with an omphalocele and a co-twin with severe intrauterine growth retardation and gastroschisis. [1] It grows during pregnancy because it is perfused by its developmentally normal co-twin (called the pump twin) via a set of placental arterio-arterial and venovenous anastomoses. The pump twin dies intrauterine or neonatal in about $50 \%$ of the cases due to congestive heart failure, polyhydramnios and prematurity.[5] Blood from the normal twin reaches the acardia through a large artery-artery anastomosis, flows through the acardia in reverse course and returns to the pump twin via a large vein-vein anastomosis. These vascular anastomoses occur at the level of the umbilical cord or chorionic plate. The acardia has no placenta-parenchymal vascular connections and is therefore more akin to a conjoined twin than a twin- twin transfusion. ${ }^{[4]}$

The two main theories of pathogenesis are:

1. The reversed circulation is responsible for regression or resorption of a previously formed heart in the acardia twin.

2. The anomaly results from primary agenesis of the heart and the acardia fetus survives only when maintained by very specific vascular anastomosis with a normal co-twin.

When karyotypic, the acardius and its co-twin have been isosexual.[4] Laure-Kamionowska M. etal studied the effects of ischemia and hypoxia on the development of nervous system in acardia fetus opined that the malformation of the nervous system might be caused by impaired induction due to altered gene expression or to the interference of the exogenous agents that interrupt normal development. [3] Umur etal used a modified hemodynamic resistance model and predicted that the pump twin has excess blood volume and increased mean arterial blood pressure compared to those in the acardiac twin. ${ }^{[5]}$

The pump twin is at risk for cardiovascular overload and preterm delivery. Hence proper timing of the delivery is of prime importance for survival of the normal fetus for which emphasis is placed on close sonographic monitoring for antenatal diagnosis.[6] 
CONCLUSION: On gross and microscopic study of the incidentally detected skin covered placental mass, a diagnosis of fetus acardia was made.This is a rare congenital anomaly which occurs due to anomalous vascular anastomoses and can produce hemodynamic changes leading to perinatal mortality in the pump twin. Close sonographic monitoring during antenatal period may help in diagnosis of this condition.

\section{REFERENCES:}

1. Habbal OA, Kenue RK, Venugopalan P. Acardia syndrome co-existing with gastroschisis in the co-twin. Clin dysmorphol.2005;14:45-7

2. Malhotra N, Sinha A, Deka D, Roy KK. Twin reversed arterial perfusion: report of four cases. J Clin ultrasound.2004; 32:411-4.

3. Laure-Kamionowska M, Maslinska D, Deregowski K, Piekarski P, Raczkowska B. Effects of ischemia and hypoxia on the development of the nervous system in acardiac foetus. Folia neuropathol.2004; 42:227-33.

4. Deborah J, Gersell, Fredrick T. Kraus, Diseases of the placenta.In: Robert J.Kurman Ed. Blaustein,s pathology of the female genital tract. Springer. Newyork. $5^{\text {th }}$ ed.2002; 23:1118.

5. Umur A, Van Gemert MJ, Vanden Wijngaard JP, Ross MG, Nikkels P. Hemodynamic resistance model of monochorionic twin pregnancies complicated by acardiac twinning. Phys Med Biol.2004; 49:205-13.

6. Sohi I, Chacko B, Masih K, Choudhary S. A case of TRAP sequence. Acardiac twin. Indian J Pathol microbiol.2003; 46:664-5

FIGURE1. Gross picture of placenta with skin covered mass and two umbilical cords.

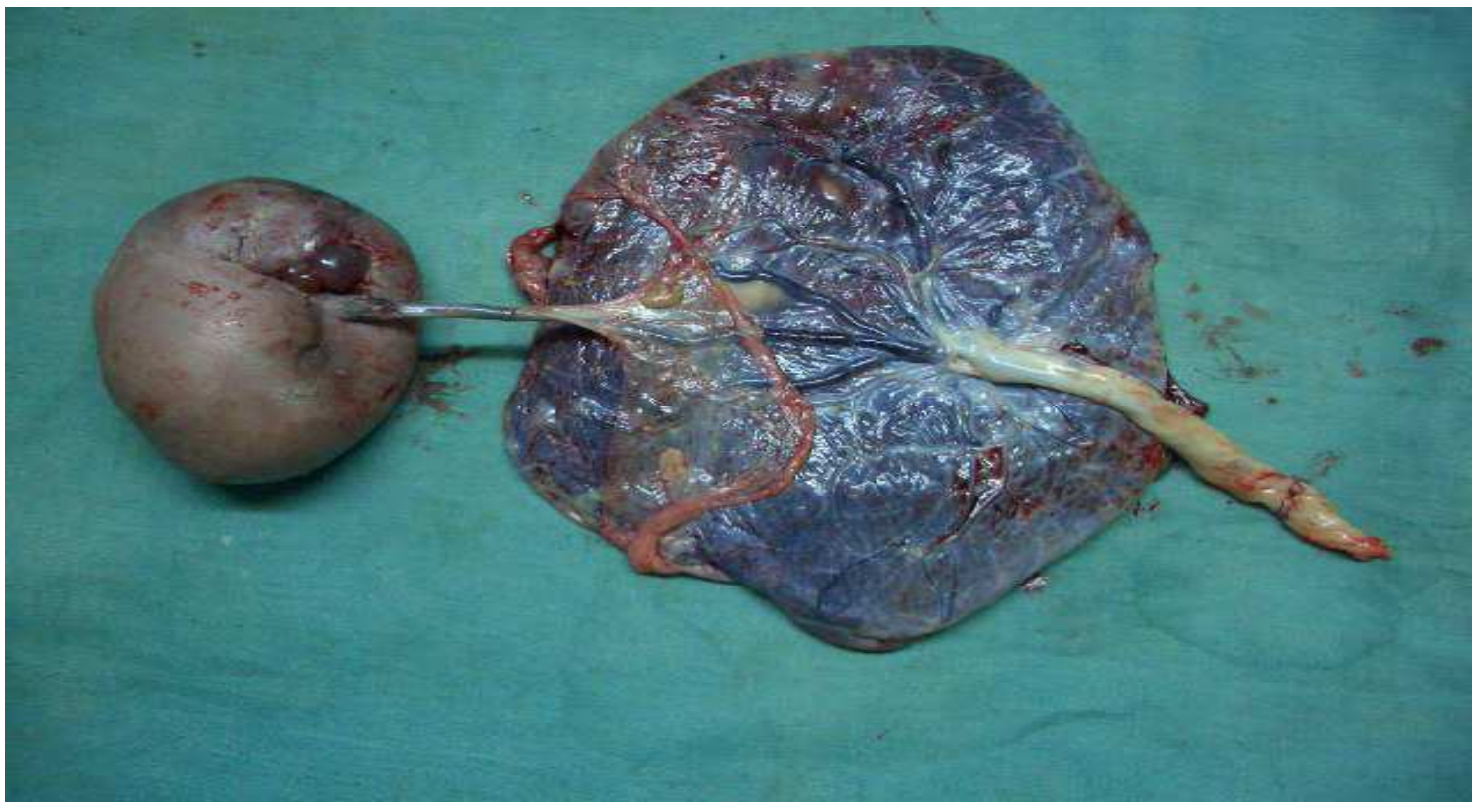




\section{CASE REPORT}

FIGURE2. Gross picture of cut open mass revealing linear augment of bony nodules in the centre.

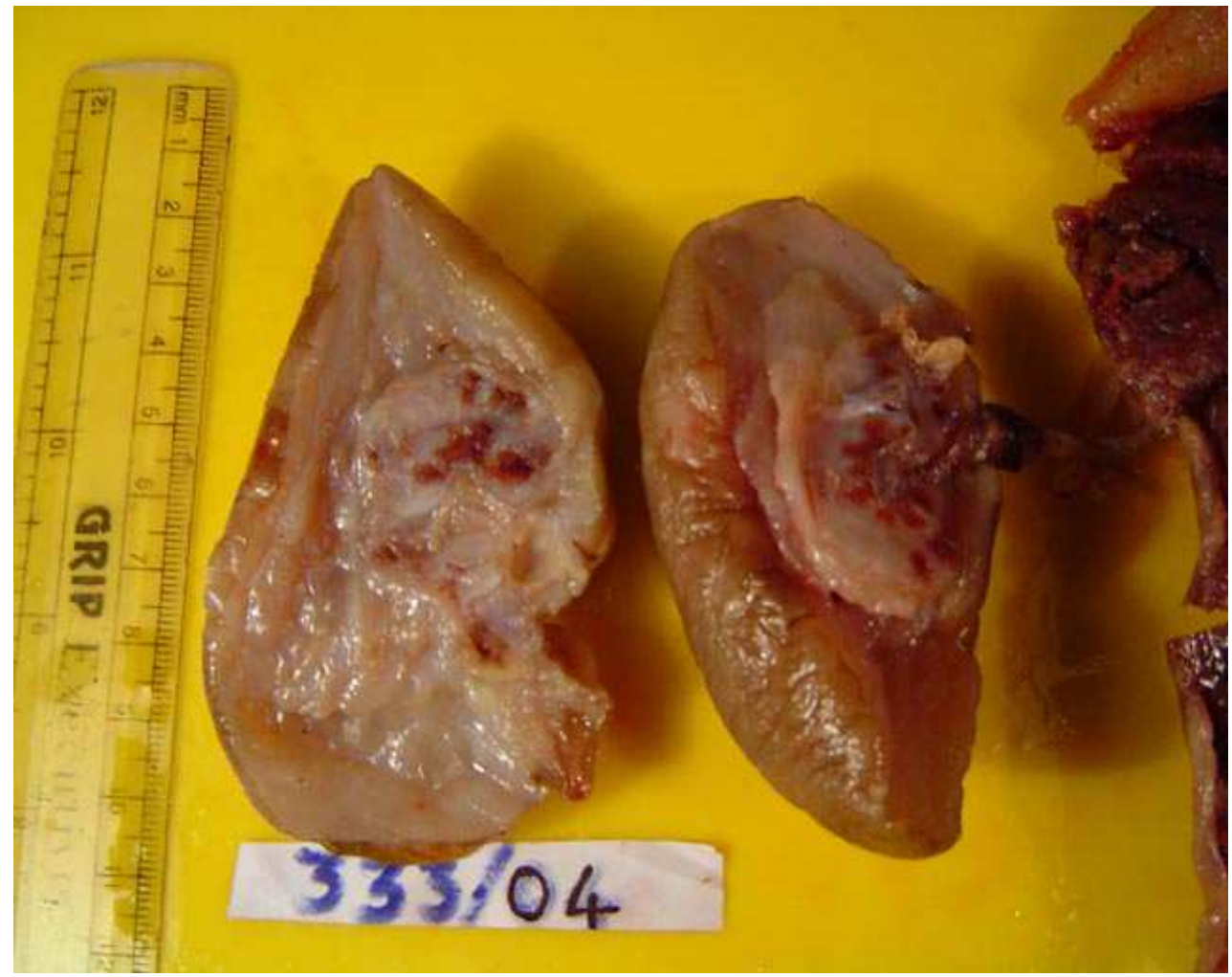

FIGURE3. H \& E 10x microphotograph of skin \& vascular subcutaneous mesenchymal tissue of the fetus acardia.

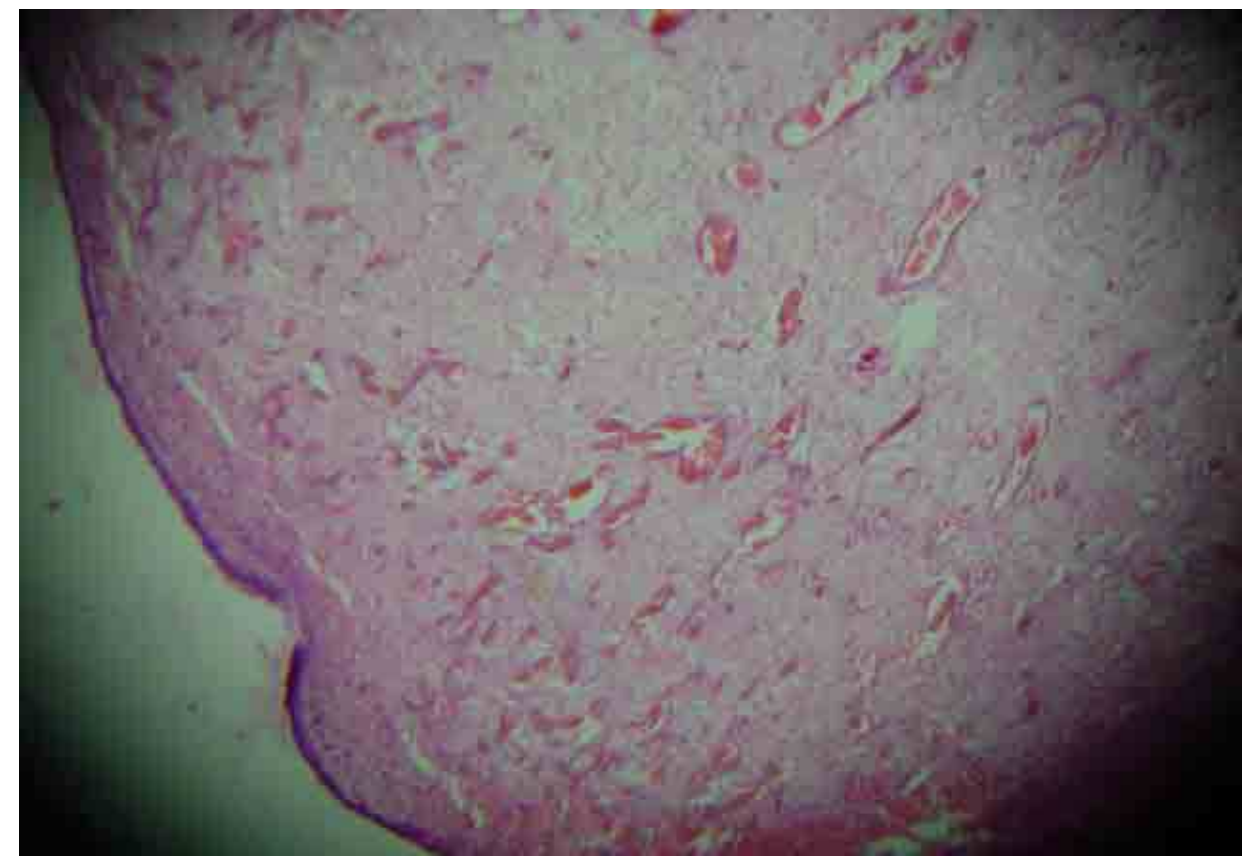

